\title{
RESTAURATION
}

\section{DE L'AGRICULTURE}

EN FRA NCE;

$$
\therefore \quad \therefore \text { T T T }
$$

MOYENS DE PREVENIR TOUTE DISETTE.

Per me rurá vigent, finè the ampliqque regna fatif cunt.

PAR UN CULTIVATEUR,

Député à l'Affemblée Nationale.

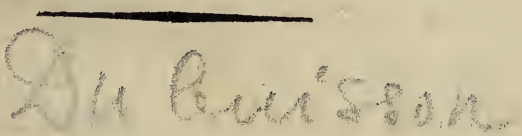

A P A R I S;

Chez BAudouin, Imprimeur de l'AssembLeE NAtionale, rue du Foin Saint-Jacques, n. 3 I

1790

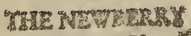

URBAKY 


\section{TRADUCTION DE L'ÉPIGRAPHE:}

C'eft l'agriculture qui parle.

Je fais profpérer les campagnes; \& fans mo les plus vaftes Empires fe détruifent. 


\section{A VERTISSEMENT.}

\section{DE L'ÉDITEUR.}

$\mathrm{O}_{\mathrm{N}}$ ne peut être heureux dans aucun Empire sans la liberté, et sans l'abondance des denrées que la liberté favorise, encourage, et qui la soutient à son tour.

Quand les ennemis du bien public veulent détruire la liberté et affamer un Peuple, pour le mieux diviser, ils accaparent toutes les denrées de première nécessité, tels que les grains farineux d'hiver; cela est très-bien vu dans leurs principes : mais ils ne connoissent pas les ressources du sol, et l'industrie du Cultivateur prévayant; elles sont infinies. Ils ne savent pas que les autres grains farineux que l'on sème au printemps, de même que toutes les

A 2 


\section{4}

cacines propres à la nourriture des hommes et des ánimaux, noưrriront tout le Royaume, quand un hiver rigoureux, ou des vues et des opérations de ces gens mal-intentionnés amèneront une disette naturelle, ou, cé qui est encore plus affreux, une disette factice.

Une famille Belge a fait, à différentes époques, depuis plusieurs siècles, des opérations agraires si simples et si utiles, qu'elles ont beaucoup contribué à lá richesse de la vaste Province qu'elle habite. C'est un des descendans de cette famille vraiment créatrice, qui expose, dans le Discours très-précis et très-sage que je publie, les moyens de ne jamais manquer de subsistances, d'obtenir et doubler en tout temps les plus précieuses productions, et celles qui peuvent remplacer notre nourriture ordinaire. Il reconnoît cepen- 
dant que cette grande ressource ne s'effectuera qu'autant que nous aurons brisé les chaînes de l'esclavage, et dissipé les ténèbres de l'ignorance. Il démontre que l'Amérique teinte encore aujourd'hui du sang des Negres, ne deviendra aussi étonnament fertile qu'elle en est susceptible, que quand elle sera cultivée par des hommes instruits et libres.

Pour que ces Peuples réusissent, il faut que l'impôt soit simple et unique; il ne faut pas établir une dîme pour l'entretien du Culte, et un autre impôt territorial. Ce seroit deux dîmes pour une, ce seroit briser toutes les charrues, ruiner en peu de temps toutes les campagnes, et absorber toutes les avances du Colon riche.

Il est bien essentiel de ne mettre qu'une dîme en impôt; toutes les autres impositions pour subvenir à toutes

A 3 
les dépenses publiques; doivent être également directes pour ne pas retømber sur le Cultivateur; les impositions sur le luxe des édifices, portes-cochères, fenêtres, carosses, etc. sucre, café, liqueurs, provenant de l'Etranger, seroient les premières; les autres sur les vins, les eaux-de-vie de France, sur les comestibles \& productions du sol; qui diminuent d'autant le pécule dans la main du premier vendeur ou producteur, seroient les dernières. 


\title{
RESTAURATION
}

\section{DE L'A GRICULTURE}

\author{
E N F R A N E E.
}

$\prod_{\text {RIP T OL È }}$ invente une charrue, laboure un champ, qui produit de quoi nourrir ceux qui le regardent ; les premiers parmi ceux-ci, qui fuivent fes leçons \& fon exemple, fe trouvent plus à l'aife; bientôt les autres les imitent. Reconnoiffans de ce bienfait, les premiers Cultivateurs; tirés des hordes fauvages, qui peuvent célébrer une fête, font de Triptolème un Dieu.

La première puiffance dans le monde connu; qui faifira ce point-de-vue, qui eft de rendre les hommes heureux, dẹ les multiplier par l'exemple de la bonne agriculture, \& l'augmentation des fubfiftances, aura des autels qui ne finiront qu'avec les élémens.

On aura beau faire des loix pour affurer les fubfiftances \& le bonheur des hommes qui fouvent ne favent pas lire; la liberté, l'exemple, le 
feul exemple de la bonne culture, dans une hxbitation, dans un territoire, peut fubjuguer \& entrainer tous les efprits groffers \& récalcitrans, à toute éxhortation écrite ou verbale, fans dire un feul mot, fans autres armes que la liberté \& l'exemple; il triomphe paifiblement des préjugés. les plus anciens \& les plus enracinés.

Le mal-aife qu'éprouve le Colon indigent luz fait ouvrir les yeux fur fon voinin qui profpère; fi le labour de ce dernier réulfit quelque temps en cultivant la terre, l'autre effaiera de marcher fur fes traces, \& de faire comme lui (moyens, dépenfes, avances $\&$ accidens à part), il parviendra à la fin anx mêmes réfultats; ils fe communiqueront de proche en proche, au póint que tous les efprits du même village n'auront plus de préjugés, penferont $\&$ agiront tous de même pour leur bienêtre réel, dependant feulement du ciel, du foleil, \& de leur labeut.

Ce moyen fimple inftruit un village voifun; par 1a proximiré \& l'enclavement du territoire, de voifin à voifin, l'intruction fe répand fans aucune autre femonce que l'infpection de la nouvelle culture de ce clramp. Ces trommes fe croient libres, \& font heureux : maitres de leurs champs \& des productions quils ont fait nitres, avec $L_{2}$ 
douce farisfaction que tout vient de leur prévoyance \& de leur induftrie; fans avoir d'autre obligation à remplir que celle d'une reconnoiffance tacite \& concentrée dans leur cour, bien flatteufe pour celui qui en eft le premier mobile \& l'Aureur. qu'il ait befoin des bras \& des forces de tous ces hommes, ils voleront avec vivacité au-devant de tous fes defirs.

Voilà, mortels, quelque parrie du monde que vous habitiez, \& dans quelque climat que vous foyez, comme vous gouverneront ceux qui voudront vous rendre heureux, \&r jouir etux-mêmes de votre bonheur.

Un bon Agriculteur, à la follicitation du Sourverain, peut fe placer dans un territoire végligé : fon exemple \& fes travaux vivifieront feuls un canton; cet homme peut former une pépinière de bons colons à tranfplanter dans tout un Royaume, \& le faire profpérer.

Un Cultivateur riche en avances commencera à en faire l'effai fans fe rebuter; à la fin il fervira d'exemple \& d'infruction à toute la communauté.

Miais le Souverain qui danne cetre première impulfion, s'il n'encourage \& ne protège les premiers efforts, sil n'empêche point la rapacité avide 
\& la fombre envie de dévorer ces premières avances \& ces premiers fruits qui ont montré la vraie fource des richeffes, sil n'y met un frein, s'il n'affeoit un impôt territorial évalué en argent, fimple \& facile dans fa perception, tout fera bientôt tari \& détruit; le champ défriché \& amélioré retournera bientôt à fon premier état de ftérilité.

O France! ô ma patrie! je gémis quand je vois tant de prés, de marais fous les eaux, tant de landes $\&$ de bruyères, tant de terres en friches quand je yois un tiers de tes terres en jachères; quel Royaume tu ferois fi tout étoit vivifié, cultivé, comme il peut E doit l'être!

Le travail que j'entreprends doit être étayé de plus grandes connoiffances, \& d'un tyle que n'omt point les gens de mon état. Fils de Cultivateur, dont le père \& les ancêtres, en fuivant la marche de la nature \& de la probité , ont toujours affez réuffi dans leurs travaux, je vais effayer de me rendre intelligible.

Il. eft évident qu'on doit commencer par cultiver les bas-fonds. Les prés ordinairement avoifinent les rivières; on trouvé plus aifément de quoi y nourrir \& y multiplier les beftiaux ; ce qui donne l'aifance de cultiver enfuite les autres. D'ailleurs, une terre vierge, adamique, \& qui eft 
inculte offre les plus grands avantages au défrichement; tous les fucs, tous les fels y ftagnent, y font incorporés depuis long-temps : les bas-fonds contiennent bien plus ces principes que tous les autres terreins. La culture va les mettre en action \& produira les récoltes les plus merveilleufes; toute l'attention du Colon eft d'en connoître la nature.

Il eft également évident qu'un excellent pré qui produit du foin très-fucculent \& en abondance, fans aucun fecours, fans aucun frais, ne doit jamais être défriché; fi la moufle l'étouffe, on peut le mettre en culture pendant deux ou trois ans, particulièrement fi le fonds eft pure glaife ou argille froide.

La première année, avant ou après l'hiver, retournez-le à. la bêche ou à la charrue; enfuite au printemps, enfemencez-le encore en avoine; la feconde année, mettez-y une orge printannière; la troifième, enfemencez-le encore en avoine, dans laquelle on sème quinze ou vingt livres de treffle à l'arpent de cent perches, qu'on donne en verd au gros bétail, tant qu'il dure; enfuite, il en broute le regain jufqu'à ce que la terre fe fourniffe d'herbes, \& redevienne encore un plus excellent pré qu'il ne l'étoit ạant le défrichement: 
Si on veut le rendro plus profitable, on doit l'aider du parque des moutons, de cendres de tourbes, de cendres-houilles, rouges \& noires, de fuie de cheminée, \&c.... Un an ou deux de cette culture fuffir pour rajetunir ce pré totalement.

Toute terre en friche, non labourée, sèche; fur le roc, fur le tuf, les rocailles, les cailloux arides, les fables fecs $\&$ infertiles, quand la charrue ne peut en retourner une certaine profondeur, doit être plantée en bois, ou refter comme elle eft, pour être broutée par les chèvres', les moutons? \& tout menu bétail, dans quelque expofition qu'elle foir.

Toutes autres terres en prés, marais oil en friche, limoneufes, argilleufes, glaifeufes, fortes ou légères, au midi cu au nord, crayonneufes ; marneufes, pierreufes, peuvent \& doivent être défrichées pour le plus grand profit, à moins qu'elles ne foient fous les eaux; \& celles-là étant defléchées, deviendront les plus frucuteufes \& les plus profitables. Dans tous les bas-fonds, il fe trouve des tourbièrés qui ferviront, $x^{\circ}$. à chauffer le Peuple; $2^{\circ}$ aux manufactures, aux brafferies $; 3^{\circ}$ à cuire la tuille, la brique, la chaux; $4^{\circ}$. à fondre les métaux, excepté l’or \& l'argent, que la tourbe, charge de bitume, de fouffre \& de vitriol, noircit; 
$5^{\circ}$. aux verreries, \&c. Les autres terres que les eaux découvriront, feront mifes en prairies ou en culturé, ou plantées en bois, fur-tout le long de tous les canaux, folfés, rigoles ou étangs, néceffaires au defféchement, ou à l'écoulement des eaux, dont on fuivra la pente qu'on connoîtra par le cours des ruiffeaux ou rivières, ou en nivellant le terrein.

Il eft inconćevable que fi peu de Souverains aient encore pris ces bas-fonds en confidération; tous les ont regardés comme des terreins perdus \& de peu de valeur. Ce font cependant les plus précieux, \& ceux qui rajeuniroient tous les autres déja mis en culture de longue main; \& defquels on peut tirer plus de produit \& de profit, foit par les nouvelles prairies excellentes qu'on gagne, \& la multiplication des beftiaux de toute efpèce, le commerce de la cire \& du miel, foit par les terres graffes \& neuves qui produiront tous les grains huileux pendant un très-long terme, fans aucune interruption; point de fole réglée, point de jachères, foit par les cendres excellentes que fourniront les tourbières; enfin par l'angmentation des bois d'aulnes, peupliers, faules, ofiers, frènes, bois blancs, \& tous autres bois aquariques.

Il n'eft pas néceffaire d'armer des vaiffeaux en 
guerre à grands frais pour aller au loin difputer à quelques hordes fauvages, des terreins qui ne font peut-être pas auffi fructueux que ceux qui font répandus dans toutes nos Provinces, dont l'infalubrité eft occafionnée par ces cloaques infects, qu'on rendroit à la fin très-falubres \& remplis d'excellens poiffons; l'impôt territorial, évalué en argent, dédommageroir bientôt le Souverain de toutes fes avances foncières, fecourables \& protectrices.

La méthode que je vais propofer n'eft point la plus difpendieufe, ni la plus difficile; elle eft connue il y a long-temps, elle eft la plus fimple \& la plus aifée.

Mon refpectable père, qui a vécu près de quatre-vingt-dix ans, n'a jamais cultivé autrement, quoiqtil ait eu deux \& trois exploitations en trois on quatre Paroiffes très-différentes par la nature de leur fol : fa pratique \& fon expérience, étoient étayées de celles de fon père \& de fon grand-père fur - tout, qui avoit vécu autant que lui (lequel la tenoit de fes ayeux); il eft le premier qui ait ofé femer le lin, colfa \& autres grains huileux dans un canton ce la Flandre. Ses defcendans ont toujours cultivé de mềme \& ont coujours réuffi, de forte quen datant de mon 
is

bifayeul, cette agriculture, toujours continuée de père en fils, peut former l'expérience de plus de deux fiècles; ce qui n'eft pas un court terme d'épreuves conftantes \& non fufpectes. Quoique je commence mon douzième luftre, je n'ai jamais vu que cette méthode ait manqué ni à moi, ni aux autres; c'eft parce que cette expérience de ma famille eft fure, que je n'héfite pas à la propofer à tous autres pour modèle, fauf à rectifier par l'intelligence ce que le pays \& le climat ne pourroit admettre.

\section{A R I ICLE PREMIER.}

\section{Sain-foin.}

Dans les fonds cultivables les plus fecs \& les plus arides, tels que les marneux, crayonneux; fablonneux, pierreux; caillouteux \& légers, qu'on peut retourner à la charrue, l'herbe la plus profitable pour tout bétail, bêtes chevalines, à cornes \& à laine, eft, fans contredit, le fain-foin verd ou fec: il eft une des premières verdures, c'eft le premier foin qu'on peut 'encore leur donner impunément aufitôt qu'il eft récolté; il les purge, les nourrit \& les engraiffe à merveille: il n'y en a aucun dans toute l'économie rụrale qui 
puiffe balancer fes avantages, pour augmenter les richefles réelles du Cukivateur, qui font les beftiaux maigres ou engraiffés , \& les élèves, fans jamais rifquer de les peràre par l'enflure, coup de fang, maladies de feu, \&c., accidens bien redoutables \& cependant bien fréquens par l'ufage de tout autre foin arificiel, ou verdure broutée \& mangée par le bétail.

Il y en a de deux efpèces: le premièr, plus commun, dont on ne tire qu'une première coupe ou fauchée, vers la Saint-Jean, quand il eft en pleine Heur, puis un petit regain qui eft encore très-précieux pour avoir dé bon lait, du beurre délicieux l'hiver, \& pour engraiffer les moutons \& les bæufs.

Le fecond; qu'on appelle en Flandre fain-foin de Barbaric ou de Hollande, dont là tige eft plis forte $\&$ plus haute, qu'on fauche auffi quand il eft en pleine fleur, \& une feconde fois quand l'été n'ett point trop fec ni trop brîlant, qui donne enfuire un excellent regain à faire brouter au betail gros \& menu. Rien de fi nutritif que cette plante; rien d'auff fain, verd ou fec; tous deux réuniffent tous les avantages que le Cultivateur peur defirer; rien ne peur les fuppléer pour leur excellence. 
Il faut avoir foin de prévoir un beau temps, par l'infpection du baromètre, pour le faucher, \& le metre enfuite en javelle avec le rateau. On a la précaution de ne pas le retourner dans la plus grande chaleur du jour, de peur de perdre les petites feuilles adhérentes à la tige, quii rendent le foin très-nourriffant; on le met en tas ou en monts, faits en pointe, de la groffeur de deux ou trois groffes futailles à l'eau-de-vie de fix à fept pieds de hauteur; qui infenfiblement s'affaiffent. On évite auffi bien la rofée que la trop grande chaleur pour cette opération, dans la crainte qu'il ne devienne poudreux. Quand les monts font bien affermis, on choifit un beau temps pour l'engranger \& l'entaffer, en le faifant bien piétiner par des liommes forts \& robuftes. Cette befogne eft peu différente de la récolte des foins ordinaires, fi ce n'eft qu'elle eft plus fimple \& plus expéditive.

Toute terre donc, femblable à cet article premier, en plaine unie ou en pente, au nord ou au midi, doit être défrichée \& retournée au printemps, à la bêche ou à la charrue, de préférence cependant avant l'hiver : il faut la femer au printemps en avoine à la herfe, l'année d'enfuite en farrafin ou bled noir ; quand le gafon eft bien Reftauration, Ec. 
pourri, la terre bien nette, on met huit oll dix voitures de fumier bien pourri, par arpent, quon enfouit à la charrue; on enfemence de nouveau cette terre en avoine, \& en même temps on y joint une livre de graine de fain - foin par perche de vingt pieds, ce qui fait au moins cent livres par arpent de cent perches; femez ce fainfoin immédiatement après l'avoine, au mois de Mars ou d'Avril, par un beau temps, on herfe légèrement un tour ou deux, puis on paffe le rouleau fur le terrein.

Si la terre eft trop sèche \& trop aride, on sème feule la graine de fain-foin au mois d'Oetobre; fi, au demi-printemps, elle n'étoit pas levée affez diue, on resème alors la moitié de la graine que l'o a mis au mois d'Octobre.

Tant que les mauvaifes herbes n'étouffent pas le fain-foin, on en fait fon profit. Cette plante peut durer, ainfi que la luzerne, 4,6 , 10, Is ou 20 ans, felon le pays \& le fol. Quand les mauvaifes hërbes fe gafonnent autour \& l'étouffent; il eft temps de retoumer alors ce champ à la charrue avant l'hiver. On doit au printemps fuivant l'enfemencer de nouveau en avoine, l'année fuivante en feigle, \& enfin en farrafin; après les trois 
années; on remet encore cette terre en fain-foin ou en luzerne.

Les meilleurs engrais pour le fain-foin font $l_{S}$ cendres de tourbes, de bois, de houille noire \& rouge, de fuie de cheminée qu’on voiture pendant l'hiver. Au printemps on laiffe mûrir cette plante, il ne faut pas attendre fa trop grande maturité pour la faucher, car elle s'égraine facilement; on la met par javelle à la rofée, puis on la bat fur-le-champ.

La graine eft bonne à donner aux chevaux aul lieu d'avoine; il faut pour cela qu'elle foit fort abondante $\&$ à bas prix : la tige battue eft bonne pour le bétail, les feuilles \& les pouffières ne font pas même à négliger; on les fert pour l'hiver, les vaches \& les moutons en tirent encore une bonne nourriture.

\section{A R T. I I.}

\section{Luzerne.}

La luzerne réuffit dans les fonds marneux? pierreux, crayonneux, glaifeux, mêlés de marne, dans les terres argilleufes, limoneufes, \& mieux généralement dans les fonds fubftanciels \& roides, que dans ceux plus légers. Dans les fonds gras \& 
20

féconds, les mauvaifes herbes l'étouffent bien vîte, elle ne dure pas fi long-temps; il faut prendre garde qu'elles n'y pullulent, autrement au bout d'un an ou deux elle périt. On sème au printems quinze ou vingt livres de feize onces de Luzerne à l'arpent de cent perches, la perche de vingt pieds dans une terre bien nette, bien meuble \& fort adoucie à la herfe \& au rouleaul : on la sème, dis-je, dans l'avoine, quand celle-ci eft haute de trois ponces, ou dans le lin, ou même feule. On empêche la première année les moutons d'y paître, \& on aura une bonne récolte le printems fuivant, $f$ on a foin de l'engraiffer pendant lhiver avec des cendres de tourbes de Hollande ou du Pays, avec des cendres dhouille rouge ou noire, avec de la fuie de cheminée, du crotin de pigeon; au printems, avec de l'urine de beftiaux, des vuidanges graffes, des mares de foffés \& de latrines, \& avec du rouffi de fumier délayé avec des tourteaux ou gâteaux de marc de colzat, de chénevis ou de linette. Quand on n'eft point ¿̀ portée d'en avoir, un feul ou deux de ces engrais fuffifent chaque année ; fans grands frais on peut fe borner à des cendres de tourbes qu'on répand tous les hivers \& tous les printemps.

C'eft la première de toutes les prairies arti- 
ficielles à donner aux vaches; il eft vai qui'elles ne donneront pas d'auffi bon lait $2 z$ d'auffi bon beurre qu'avec le fain-foin \& le trèfle verd; nais comme cette plante paroît la première, elle donne le moyen d'attendre les autres verdures. C'eft un excellent foin pour les chevaux, il leur. donne beaucoup d'embonpoint \& de viguetir; il faut cependant lui laiffer jetter fon feu dans le tas ou dans la meule pendant un mois ou deux, avant de la leur faire manger; il pourroit occafronner différens maux.

L'avantage fingulier de la lúzerne bien fumée eft d'être fauchée trois ou quatre fois ; un arpent peut produire en foin ou en verdure autant que trois bons arpens de toute autre prairie naturelle : voilà pourquoi il eft toujours bon d'en avoir pour la multiplicarion des beftiaux ; elle fupplée au fainfoin \& au trèfle, qui quelquefois manquent ou ne réuffiffent point; il faut remarquer qu'elle eft très-dangereufe à faire brouter en verd par les vaches \& moutons : elle les gonfle comme un ballon, \& les fait créver en très - peu de temps par la fermentation exceflive qu'elle excite dans leurs eftomacs. Les conducteurs de ces animaux doivent être fort prudens, circonfpects $\& z$ attentifs pour les $y$ faire manger; car une heure fuff $t$ 
pour perdre tout un troupeau de bêtes à laines ou à cornes. On doit attendre les gelées, \& on évite de leur mettre le nez au vent, fur - tout quand il eft au nord; on les chaffe de temps en en temps fur les chaumes, ou fur les jachères voifines.

Au refte, on doit avoir la même précaution pour faire paître des trèfles; une Luzernière peut durer, ainfi que le fain-foin, cinq, dix, quinze ou vingt ans, quand t'herbe ou la dent du mouton ne la font point périr, on la fait faner auffi comme ce dernier. On la lie quelquefois en bottes pour la mettre en meule ou en grange, elle s'entaffe alors mieux. C'eft un trèsbon foin pour les chevaux, l'hiver \& le printemps; il échauffe, anime, nourrit \& engraiffe; fur-tout quand il n'a pas eu de pluie, \& qu'il n'eft ni poudreux, ni moifi ; il eft bon aufi pour les moutons.

Quand la luzerne ne produit plus abondam ment, \& qu'elle eft trop enherbée, on la retourne à la charrue; cette terre alors rapportera de bonnes avoines \& de bons colzats, enfuite des feigles, des vefces mêlées de feigle, \& enfin du froment, fi la'nature du terrein le permet. Si cette terre eft bien nette \& aidée de 
bons engrais, elle produira autant que d'autres bonnes terres en culture, fur - tout fi le colzat fufdit eft cultivé à la manière flamande, comme elle eft enfeignée dans le journal d'agriculture; par M. l'Abbé Roubaut, mois de Février 1778 , page 65 , \&c. C'eft la meilleure méthode \& la plus profitable pour rajeunir le fol; on ne fauroir affez la faire connoître.

\section{$A \approx$ T. I I I.}

\section{Trèfle.}

Le trèfle demande une bonne terre $\&$ de bons fonds, fur-tout d'argille un peu roide, rouge $\&$ en bon état de culture \& d'engrais; il ne convient pas du tout dans un fonds marneux, crayonneux, pierreux, \& généralement dans toutes les terres fort lágères \& sèches, c'eft-à-dire qu'il n'y réuffit jamais auffi bien; cette plante eft bien plus friande que la luzerne \&a le fain-foin : ce dernier fur-tout qui vient parfaitement bien dans toutes les terres prefque infertiles, les rend même fufceptibles, quand on les défriche, de porter avec profit d'autres grains, tels qu'avoine, farrazin, feigle mêlé de lentilles \& vefces.

Le trèfle cependant eft, après le fain foin; 
is meilleure nourriture à donner en verd dans l'étable aux vaches \& aux chevaux; il fournit de trèsbon beurre \& dans la plus grande abondance; on le coupe quand il eft en pleine fleur, jufquà deux \& même trois fois; fur-tout quand on l'aide, comme la luzerne, de cendres $\&$ des mêmes engrais avant $\&$ après l'hiver ; il eft plus difficile à récolter fec que le fain-foin; avec du beau temps on en vient cependant à bout, quand il a effuyé beaucoup de pluie; il eft poudreux, mauvais \& dangerctix, principalement pour les chevaux, ainfi que le foin de luzerne: il faut auffi le laiffer fuer en tas, un mois ou deux. S'il eft poudreux, on le donne l'hiver aux vaches \& aux moutons, après l'avoir fecoué avec attention; fa fenaifon \& fa récolte font les mêmes que celles du fain-foin \& de la luzerne, fi ce n'eft qu'il faut le remuer \& le retourner tant qu'il foit auffi fec que le foin de Pré, pour le mettre en monts ou petits tas. Dans le champ même le dernier regain qu'on ne fauche pas, eft une bonne nourriture pour les vaches \& pour les moutons; il faut les mêmes précautions pour le faire brouter, que pour la luzerne, afin de ne pas les perdre par l'enflure.

On sème quinze ou vingt livres de trèfle $d$ l'arpent de terre, au printemps, à la veille d'une 


\section{5}

pluie, dans les avoines levées, dans les bleds \& dans les feigles verds : on paffe légèrement un trainoir fur le femis: quand on veut en tirer de la graine, on ne fauche pas ordinairement la feconde coupe, on la laiffe mûrir à fond; on bat la graine l'hiver par une gelée sèche, on sème la paille courte, on la gouffe au mois de Février dans les Prés ou dans les bleds verds, \& fouvent il réuffit mieux que de femer la graine pure. Après la moiffon, on a quelquefois un bon regain à faire paître, puis l'année d'après il eft dans toute fa force; l'année fuivante, on le fait manger par les agneaux ou autre bétail jufqu’à la Saint-Jean ; on le retourne avant l'hiver pour en tirer une très-bonne avoine ou un bon lin non ramé.

\section{$A$ R T. I V.}

\section{Ray-Graje.}

Le ray-graffe ou faux bled, dont la graine doit être tirée d'Angleterre, réuffit dans tous les fols, \& donne un excellent fourrage pour les boftiaux; fa culture, fa récolte eft la même que celle du fain-foin ; on doit avoir la précaution de le faucher quand la tige commence à contenir l'épi formé : 
on peut le faire paître en verd au commencement da printemps; verd ou fec il fortifie, entretient en bon état \& engraiffe. Cette plante réfifte quelquefois, quand les trois autres périffent par un hiver rigoureux; elle eft encore de la plus grande reffource pour le laboureur, mais bien des perfonnes s'en paffent.

$\mathrm{Au}$ refte, dans toute exploitation il faut réunir la culture de ces efpèces, principalement des trois premières, pour la nourriture \& la multiplication des beftiaux, parce que l'un fupplée toujours au défaut de l'autre; tous ne réuffiffent pas toujours également chaque année. L'Agriculteur qui multipliera fes beftiaux élevés chez lui, par ces nourritures \& les autres que je vais citer, fera tout profpérer dans fes terres enfemencées, foit de bled, de feigle, d'avoine, de colfat \& de lin, \&c. Par l'abondance des fumiers \& des engrais de toute efpèce, il engraiffera des beftiaux à volonté; il choifira, par curiofité, pour élèves, les plus beaux dans chaque ef́èce, fans jamais être dérouté, fans jamais être pris au dépourvu. Ses voifins émerveillés, en feront antant, \& bientôt toute une Province pourra l'imiter $\&$ s'enrichir à fon exemple. Qui empêche qu'une Province voifine fuive la même méthode, \& très-facilement, par le com- 


\section{2)}

merce \& les relations qu'un voifin a effentiellement avec fon voifin, \& enfin tout un Royaume.

Tout ce que j'ai propofé jufqu'ici n'a rien de commun avec les terres ordinaires en droite fole ou en jachère; ce que je vais dire dans les cinq articles fuivans, n'y aura pas plus de rapport; c'eft-à-dire que les terres en bled ou en avoine, condamnées aul repos (par lignorance, la pauvreré, ou l'impôt mal affis \& arbitrairement perçu), feront toujours cultivées à l'ordinaire : je n'y dérange rien, ou bien peu de chofe; cependant par gradation \& avec le bénéfice des engrais \& la multiplication des beftiaux, infenfiblement toutes les jachères diminueront, jufqu'aul point de les fupprimer entiérement; le tout au profit du commerce. Les denrées capables de vivifier les manufactures, telles que tous les grains huilleux, comme chanvre, lin, colfat, camomille, œillettes, \& $x$. Ia régénération \& l'amélioration des troupeaux, \& la fineffe des laines que le fol de la France peut produire avec autant \& plus d'avantage que l'Efpagne \& l'Angleterre, feront uné nouvelle fource de profpérité que je veux trouver dans la troifième partie du fol, qui forme les jachères ou l'année de repos : on trouve encore plus aifément ces richeffes, qui vont animer l'inertie des jachères, dans 
le defrichement de tous les marais noyés fous les eaux, formés en pré naturel, ou prairies artificielles, ou en culture ordinaire; ils donneront des nourritures notvelles pour multiplier le bétail, les fumiers, \& les fubfiftances des hommes; toutes celles propres à être mifes en bonne \& floriffante culture, fans ces apprêts, n’y dérangeront rien; tout au contraire, en agriculture, une partie défrichee, anime, vivifie l'autre qui eft en culture; rien d'inutile, point de coup perdu.

Je m'arrête. Rien de tout ceci n'arrivera, fi le Souverain ne tient point le timon de l'Etat, s'il ne protège \& n'encourage le laborieux $\mathrm{Cul}$ tivateur. Hélas ! il peut le faire de la manière la plus aifée \& la plus fimple : c'eft de lui permettre de vendre librement fes denrées, c'eft de l'empêcher d'être vexé, ruiné \& avili par les fuppôts de la chicane' qui, s'impatronifant dans une honnête famille, comme font les chenilles dans un jardin rempli de légumes, d'excellens arbres fruitiers, commencent par en ronger les feuilles, puis les fruits, \& en peu de temps defsèchent \& dévorent le tronc \& les racines.

C'eft ici qu'un Monarque éclairé doit preadre la coignée du. Sauvage de l'Amérique, dont Montefquieu fait une application fi jufte; c'eft 


\section{9}

ici, dis-je, qu'il doit frapper avec des bras d'Hercule, \& délivrer l'univers de cette hydre maudite, de ces exécrables harpies, oifeaux plus fombres \& plus funèbres que ceux du lac de Stymphale, portant la trifteffe, la défolation \& la mort par-tout où ils fe montrent.

Heureufes les Nations où un Héros pacifique, un Roi fage faura prendre la réfolution ferme de couper toutes les têtes de ces monftres odieux, \& de détruire à jamais dans fes Etats tous les germes de cette horrible engeance. Supérieur à Cadmus, qui n'avoit d'autre talent que de faire naître des hommes, il aura celui de les multiplier, de pourvoir à leur fubfiftance, de les empêcher d'être dévorés par les plus infâmes dragons. L'apothéofe qui couronna les travaux d'Hercule, n'eft qu'un foible hommage au prix de celle qui fera due par les mortels à ce Héros bienfaifant.

O fages defcendans de Guillaume Penn ! ne vous laffez point de verfer votre fang pour conquérir la liberté que l'Auteur de la nature a donnée à tous les êtres. Si l'Europe tarde trop à fecouer le joug des préjugés \& des preftiges qui rendent les hommes foibles \& pufillanimes, vous aurez la gloire de lui en donner l'exemple dans un vafte hémifphère. 
$30^{\circ}$

Après avoir annobli votre race par de fi pénibles efforts, après avoir établi un impôt unique \& fimple fur le revenu des fonds territoriaux; il vous reftera bien peu de chofe à faire pour le bonheur de vos defcendans; prenez les moyens fages d'empêcher à jamais que la rapacité des fuppôts de la finance \& de la chicane ne s'empare de vos foyers \& ne s'y établiffe, pour vous fubjuguer \& vous replonger dans les ténèbres dont nos régions font couvertes, que votre courage diffipe, \& dont je voudrois voir notre continent délivré. Empêchez par des Loix immuables que les Seigneurs féodaux n'arrêtent \& n'anéantiffent les premiers efforts du talent \& de la conftance par des vexations \& des tyrannies qui feroient tarir la fource de tous les biens; ne fouffrez pas que certains célibataires comblés des bienfaits du Gouvernement, aillent abforber les richeffes \& les avances de vos Cultivateurs , \& faffent fuir les riches Colons de vos campagnes; en affichant un luxe révoltant \& fcandaleux dans des Provinces affermies au prix de votre fang; empêchez que leurs agens \& leurs efclaves ne dévorent les travaux \& les mifes de l'Agriculteur laborieux par l'inftabilité des baux, par des redevances \& des fermages exceflivement hauffés, \& 
fi exhorbitans; qu'un bon père de famille \& un prudent Adminiftrateur n'oferoient jamais les exiger. $\mathrm{Ne}$ fouffrez jamais que l'égoifme affreux qui dit, après nous le déluge, s'établiffe chez vous, il y produiroit plus de maux, il y feroit plus de ravage que n'a fait jufques aujourd'hui l'Anglois \& le fcapel du fauvage.

Il faut que chaque Colon foit maitre de fon champ, comme il a le droit d'y extirper les mauvaifes herbes, d'y détruire les infectes, vermeaux, mufaraignes, \& tout ce qui peut nuire à fes efpérances \& fes récoltes, il doit avoir de même le droit d'écarter \& de tuer le lièvre, le lapin, la perdrix \& le faifan qui ravagent fes vignes, fes grains, à plus forte railon, la biche, le cerf, le fanglier, le loup qui dévore fes brebis, \&r enfin tout le gibier qui peut ravager fes moifons. C'eft ici que la fermeté du Gouvernement doit fe montrer invariable \& protéger avec vigueur le foible opprimé par le puiffant dépourvu de raifon \& d'humanité : autrement les loix les plus fages font bientôt renverfées; un Seigneur féodal, jaloux de la chaffe, tracaffera, vexera \& ruinera, en peu de temps, le pauvre $\&$ le riche Cultivateur.

Les gens de Loi, Greffiers, Baillis, Procureurs; 


\section{2}

Gardes, Sergens, tout le cortège de la chicane, qu'il a à fes ordres, vont bientôt affiéger l'innocent Agriculteur d'un déluge d'écriture les plus uniformes qu'il n'entend ni ne peut lire; il abandonne auffitôt en gémiffant les plus juftes prétentions que doivent mériter fes vigoureux travaux; il finit fouvent par être honni, \& par mourir dans la plus affreufe misère, pour avoir défendu trop librement ce que fes bras, fes enfans, Dieu \& la nature avoient fait naîrre. Barbarie qui. glace d'effroi tous fes femblables; injuttice, qui n'eft que rrop commune dans plus d'un pays.

O Penfylvaniens, ennemis de l'oppreffion \& 2 protecteurs des propriétés! vous peuplerez \& enrichirez, en peu de temps, vos régions de la claffe la plus laborieufe \& la plus intelligente des Européens qui ont de l'ame $\&$ du courage, à moins que des Loix plus fages de réformes, de protection \& d'encouragement n'oppofent une forte barrière à leurs émigrations ( 1 ).

(I) Note de l'Editeur. L'Auteur écrivoit ceci en 1783 , ce qu'il difoir alors aux Américains peut très-bien s'appliquer aux circonftances aetuelles de Ia révolution.

ART. V. 
A R T. V:

\section{Pomme de terre.}

Les terres limoneufes, fablonneufes, argilleufes, bien cultivées, bien nettes \& ameublies, plus légères que roides, conviennent à la pomme de terre $\&$ all topinambour. Ce fruit réunit tous les avantages pofibles pour les hommes, les beftiaux \& les volailles de toute efpèce ; étant cuite \& broyée on en fait de très-bon potage pour les gens de travail avec légumes, comme choux, navets, carottes \& ris en temps de diferte ou de cherté de grain, elle y fupplée avec un grand avantage : toutes les moiffons feroient détruites par l'orage \& la foudre, par les tempêtes \& les grêles les plus défolantes, le Cuitivateur trouveroit encore les pommes de terres, les carottes, les panais, les betteraves, les navets, qui l'empêcheroient de mourir de faim, lui \& fon bétail ; c'eft ponrquoi on ne doit jamais négliger de cultiver ces racines, qui, hors de ces années de calamité \& de défaftres, procurent tous les moyens faciles de s'enrichir par l'engrais des beftiaux, \&c. La tige; all commencement d'Octobre, nourrit les vaches; le fruit cuit dans l'eau \& broyé avec du fon, nourrit Reftaurat. de l'agriculture, Ec. C 


\section{4}

dindon, oie, chapon, canard \& toute forte de volailles. La pormme de rerre engraiffe les porcs étant mêlée de mouture de feigle, d'orge \& \&x farrafin. Si on en fait bouillir avec des tourteaux ou gâteaux de colf $t$ \& de chenevi ou avec des criblures dé linetres ou de la mouture de feigle ou de farrafin, elle engraiffe les vaches \& les boufs; outre cela, on en fait d'excellent pain, d'excellentes pâtifferies, \& de très-bons mets, fort légers. IVI. Parmentier de Paris a donné un très-bon traité fui cette fabrication oui ne laiffe rien à defirer; la pomme de terre donne encore d'excellent amiton à faire de la poudre pour les cheveux, ce qui eft cncore un objet de très-grande écono= mic. Ie ne vois rien dans la nature qui puiffe downer des bénéfices fi réels, \& en auffi grand nombre; un arpent de terre bien arrangé fournit plus de profit au Cultivateur, que toute autre production, excepté le lin ramé, quand il réuffit. Sa culture eft la plus aifée, comme elle eft la plus fructueufe. Les fonds fablonneux \& gras ou engraiffés, les fonds limoneux, \&c. font excellens pour fetre plante.

- Au mois de Février ou de Mars, par un temps fcc, il faut labourer la terre qu'on aura bien fümée avan l'hiver, la rendre meuble \& douce, la bien? 
herfer \& la bien nettoyer des mauvaifes herbes? à la fin de. Mars ou au commencement d'Avril, on doit, par un beau temps, s'il eft poffible, enfouir à la bêche ou à la charrue les pommes de rerres moyennes, ou les groffes coupées en deux ou en trois felon leur groffeur, \& les placer $\grave{a}$ trois pieds de diftance.

Quand la pormme de terre eft levée \& qu'elle pouffe en verdure, on prend une bêche ou plutôt une houe, on extirpe toutes les rauvaifes herbes en ratiffant au tour de la plante fans l'étouffer; quand la tige eft élevée $\&$ haute d'un demi-pied, on recommence cette opération, l'on ratifle toujours auprès de la tige pour y former une motte, où les pummes de terre fe plaifent à pulluler.

On redonne encore une troifième \& mêtme façon à la fin de Juin ou au commencement de Juillet; felon que la faifon s'avance plus oi moins, empêchant toujours l'herbe de croître près les mottes; que l'on forme à la fin comme une groffe taupinière ; cette dernière façon eft fouvent inutile quand il n'y a point d'herbe, \& que la motte eft fuffifamment groflie. On peut même les planter \&r rehauffer à la charrue, ce qui eft bien moins difpendieux.

Au mois d'Octobre, on fait la récolre par un

$$
\mathrm{C}_{2}
$$




\section{6}

beau temps; un homme enlève la motte avec la bêche ou un trident, il refte ordinairement trèspeu de ces pommes dans le fond: de petites filles \& de petits garçons font aux aguets, fecouent toute la térre des tiges, \& les ramaffent; l'on met ces pommes dans une cave pour les conferver \& les garantir de la gelée; au mois de Février, on les met au grenier, où elles fe confervent jufqu'aux nouvelles; il eft furtout effentiel d'en faire l'extraction plus tôt que plus tard', \& par un beau temps, de peur que la gelée ne l'atteigne \& l'empêche de fe garder; on doit préférer la groffe blanche tirant fur le jaune \& un peu applatie, à toute autre efpèce, parce qu'elle réfinte mieux aux premières gelées, \& parce qu'elle eft un peu plus enfoncée en terre, cuoiqu'en général toutes cherchent la terre douce, légère, ratiffée \& rapportée au haut de la groffe motte : cette récolte donne par le remuement un bon labour à la terre qui eft déja bien nettoyée : après cette opération, on :bine \& on laboure le champ, on l'enfemence en bled dans la même année, comme toute autre terre en jachère, ou, pour mieux réuffir, en bled de Mars, en orge, ou paumelle, dont tout Cultivateur protdent doit 'toujours avoir une portion en réferve, pour fuppléer aux grains d'hiver péris ou gelés; 
les Gouvernemens devroient même encourager la culture de ces grains printaniers, qui empêcheroient une difette défaftreufe, \& obvieroient à de grandes calamités. Ce fol bien ameubli par les façons données à la pomme de terre \& par fa récolte, qui équivalent aux labours des terres en repos, rapportera donc encore un bon bled \& d'autres bons grains de Mars.

\section{A R T. V I.}

\section{Carotte.}

On sème les Carottes depuis le Is de Mars jufqu'au Is d'Avril, felon le temps qu'il fait; le plus tôt eft le mieux; deux livres \& demie à l'arpent fuffifent. Elles récuffiffent à merveille dans les terres douces \& limoneufes, dans des fonds ou vallées argilleufes, mais pas trop roides. On laboure ces terres avant l'hiver à la charrue ou à la bêche, d'un bon pied de profondeur; il faut adoucir la terre, au printemps, avec la herfe, femer, puis herfer le femis.

Quand les Carottes font bien levées, on nettoie les mauvaifes herbesà la main ou avec la houe, on ratiffe bien la terre, \& on les réduit à un demi-pied l'une de l'autre; on redonne encore un fecond travail 


\section{$3^{8}$}

a la houe pour détruire les mauvaifes herbes, jufqu'ă ce que le verd des Carottes couvre la fuperficie du terrein. Au commencement de Novembre, on arrache les Carottes; on coupe le verd; excellent pour le gros bétail, on met les racines à l'abri de la gelée, en ras ou dans de grands trous qu'on recouvre de terre comme une tombe; on conferve de même les pormmes de terre \& autres racines. C'eft une excellente nourriture pour les vaches: elles donnent d'auffi bon lait thiver qu'on" puiffe le defirer. Cette plante rafraîchit les chevaux \& les engraiffe. Enfin, tant que la luzerne ne foit venue, elles font le plus grand profit dans une exploitation; plus on en a, mieux on s'en trouve. On sème également du bled après les Carottes; comme après les ponmes de terre. Je ne parlerai point des panais, bettraves $\&$ racines de difette, parce que ceit la même culture, quion en retire le même profit que des Carottes. Il eft effentiel que tout Cultivateur ne néglige pas plus leur culture que celle des Carctres. 


\section{$A$ R. $\mathrm{T}$ I I.}

\section{Navet.}

On sème les Navets communs, ronds \& plats au mois de Juin, vers la Saint-Jean, dans une bonne terre douce, bien fumée ou bien grafte; on met à-peu-près une livre de graine à l'arpent. Quand les Navets font levés, \& quills ont deux ou trois feuilles, on y jette l'urine des beftiaux; cetre opération doit être faite à la veille d'une pluie, rien n'accélère plus leur croiffance, ils deviendront très-gros. Le Navet \& fa verdure font excellens pour les boufs \& les vaches, perfonne ne l'ignore; il faut en avoir en tout temps; autant que faire fe peut, mais particulièremént l'hiver, on en tire le plus grand profit. On engraiffe des boufs \& des vaches avec les carotres, panais, bettraves \& les feuilles de haut choux; celles-ci donnent alors autant de lait \& d'aufi bon beurre qu'en été.

On sème encore des Navets après la récolté du feigle, quand la terre n'eft pas maigre; mais il faut fur-tout femer au mois de Juin ou Juillet la rabba ou turnips: c'elt la rabbiola des Provinces méridionales de France, elle fort de 


\section{0}

cerre; n'y tient que par le bout de la racine; elle devient très-grofle; c'eft une excellente nourriture pour les bêtes à cornes \& les porcs, \& orr doit toujours en femer beaucoup pour en avoir tout l'hiver, \& les conferver comme les caruttes, panais \& bettraves dans des trous faits en terre: On sème également du bled de Mars ou d'hiver après les Navets comme après les autres efpèces précédentes.

\section{$A_{\mathrm{R}}$ T. $\quad \mathrm{V}$ I I I.}

\section{Choux.}

On sème la graine de haut choux dans une bonne terre bien graffe \& bien fumée, au mois de Mars ou Avril; on les replante au mois de Juin dans une terre voifine de la ferme \& des étables, ainfi que les carottes, panais, bettraves, navets \& pommes de terre; on les a plus tôt fous la main \& on ne perd pas tant de temps par les voitures; on les engraiffe avec l'urine des beftiaux: ils viennent alors de quatre pieds de hauteur; on ratiffe auffi autour du pied, il doit être à trois pieds de diftance; la tige eft toute garnie de feuilles depuis le haut jufqu'en' bas, on arrache celles d'en bas toujours les premières au mois de 


$$
4 r
$$

Novembre \& Décembre, on en fait de très-bon breuvage pour les vaches avec du fel, du fon ou de la mouture, \& fur-tout pour les élèves; rien ne les fortifie mieux \& rien ne les empêche tant de languir ; on doit toujours en avoir beaucoup, ils réfiftent le plus long-temps à la gelée. Cette graine eft très-commune en Flandre, une livre fuffit pour un arpent lde terre, ainfi que les navets \& le colfat. Il faut que le fel foit commerçable \& point coûteux ; il eft auffi effentiel à là fanté des animaux qu'à celle des hommes. D'ailleurs, le fumier acquiert une qualité exquife $\&$ précieufe pour les terres, quand on donne du fel aux beftiaux.

\section{A R T. I X.}

$$
\text { Ris - Jec. }
$$

$M$. Poivre a rapporté de fes voyages une ef pèce de $\mathrm{Ris}$ connu à préfent en France, \& qui y réuffit très-bien ; on le sème $\&$ on le récolte dans. un terrein fec, fans qu'il ait befoin d'irrigation, d'où lui vient le nom de Ris-fec. C'eft la même culture que pour la paumelle, l'orge printanière $\&$ les autres grains de Mars; il feroit d'une grande reffource devenant indigène. On fait combien ce 
grain eft urile dans les temps de difetre, \& combien l'ufage en eft agréable \& falubre, au milieu même de l'abondance. C'eft pour tous les âges de la vie un mets délicat \& fain; fa culture eft facile comme celle des autres grains de Mars : il exige auffi peu de dépenfes que de foins. On peut le joindre à prefque tous les autres alimens; les Indiens qui font bien plus près que nous de l'heureufe fimplicité de l'âge d'or, préfèrent le Ris à toute autre nourriture, \& cet excellent fa-, rineux contribue à leur rendre le fang pur $\&$ calme, \& par conféquent le caractère doux.

Cependant, joint avec les viandes que notre agriculture produira plus abondamment, il fera un aliment fort \& folide qui influe néceffairement fur un tempérament robufte; il faut le propager dans nos campagnes où règne trop de misère.

La multiplication des beftiaux produira une abondance de fuif, de beurre, \&c., qui, enrichic l'Irlande. Le commerce des groffes \& menues falaisons, de pelleteries nous fera fortir moins de numéraire pout les cuirs de Hongrie \& antres, qué notre induftrie ápprendra bientôt à façonner: nous pourrons mêrne en fournir aux étrangers. Que de richeffes perdues pour nous, parce que 


\section{3}

nous laiffons notre fol dans l'inettie, que l'induftrie françoife faura bientôt vivifier au-delà de ce que, je puis exprimer.

Or, je fuis perfuadé qu'on peut totalement fupprimer les jachères, d'abord dans les bons fonds, puis dans les médiocres, \& graduellemene dans les mauvais fols, par les fecours des prairies ártificielles, des beftiaux \& des fumiers \& autres engrais, \& du fel \& du tabac vendus librement ; parl'abolition des fuppôts de la Gabelle, des Aides \& autres Vampires du Royaume ; enfin par un impôt unique \& direct, mis fur les revenus des fonds ruraux \& autres. Toutes les impofitions indirectes font ruineufes, \& détruifent les richeffes des champs \& du labourage.

Le 'monopole n'affameroit jamais un pareil Royaume; ceux qui voudroient l'affamer, femblables à Tantale, mourroient plutót de foif \& de faim au milieu de leur or \& de leur argent, \& le Laboureur vivroit tranquillement avec fes denrées \& fes beftiaux, il repoufferoit de fes bras nerveux celui qui voudroit l'armer contre fes Concitoyens en lui promettant des richeffes qu'il méprife, parce qu'il n'en a aucunement befoin. 


\section{4 \\ A R r. $\mathrm{X}$.}

\section{Tabac.}

Les bas-fonds, gras, noyés ou expofés à l'être, de quelque nature qu'ils foient, doivent avant tout être faignés par des foffés dont un bout au midi, \& l'autre au nord, \&, fi les premiers ne finfifent point, par des foffés tranfverfaux. La terre tirée des foffés, fi elle fe trouve toujours d'une nature bien graffe, mêlée avec celle de la fuperficie, pourra être mife auffitôt en culture, à moins que ce ne foit des cailloux, rocailles, crayon on tourbes, \&c. On y plante ou repique du tabac au printemps, femé avant dans une couche ou dans un jardin ou terre forr graffe \& fumée; on ratiffe la terre autour, quand la plante s'élève, comme aux pommes de terre; tous les rejets laréraux \& ceux du fommet qui veulent monter en graine doivent être coupés, à mefure qu’ils fe montrent, avec l'ongle du pouce : il doit être planté en rangées égales; les rangées font à deux pieds l'une de l'autre, \& chaque plante à un pied de diftance, on laiffe croître huit ou neuf fevilles avant de châtrer la fommité,'il demande beaucoup d'affiduité pour couper les rejets laté- 


\section{5}

saux \& pour ratiffer \& remonter la terre autoux de chaque plante; mais des femmes \& des potits enfans font cette befogne fans bealicoup de peine (I).

Les tabacs venus en maturité, même dans des fonds feptentrionaux \& très-froids, ne laiffent point que d’être recherchés par les Marchands qui les font paffer pour des tabacs de l'Amérique \& des Pays lointains, quoiqu'ils en fafrent les dégoûtés pour les payer au plus bas prix poffible ; c'eft une branche d'induftrie qu'aucun Souverain ne doit négliger, puifque l'ufage en eft devenu auffi univerfel, \& qu'il pourroit ramener un numéraire immenfe payé par l'étranger; on coupe la tige avec les feuilles, on les met en groffes bottes qu'on emporte pour faire fécher contre les parois \& les couvertures des maifons \& des granges couvertes de chaume, puis on l'effeuille l'hiver, quand il eft fec, pour le mettre

(I) Il eft sûr qu'on paie douze millions à l'Etranger pour les tabacs importés; fi la cu ture en étoit libre en France, on pourroit en vendre pour douze millions aux Peuples voifns, \& avoir fa confommation fans nuire aux autres cultures. On fe pafferoit de Commis, de régie, qui tue \& tuera tonjours toute économi rurate. 


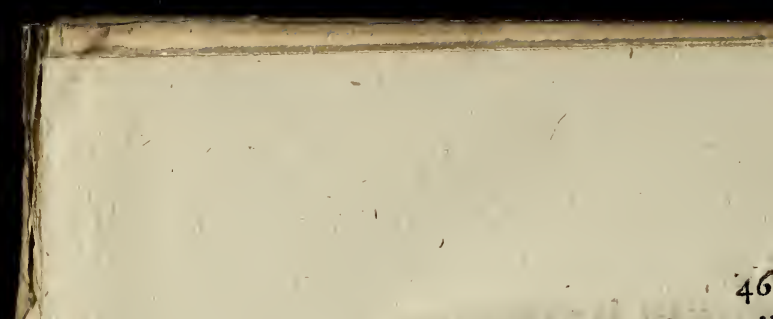

en maffe au grenier, il eft alors bon pour $\mathrm{l}_{2}$ vente.

Après le tabac, on met encore du bled de faifon, ou de Mars, ou d'orge d'hiver, comme après les pommes de terre, les panais, bettraves \& les navets; je parle ici de la culture de cette plante, parce que je crois que c'eft une trèsgrande perte pour les Souverains qui la prohibent dans leurs Etats. Les Entrepreneurs-généraux qui en ont la manutention \& l'adminiftration exclufive, mafquent $\&$ décrient autant qu'ils peuvent l'excellence des tabacs européens, pour en tirer' un profit centuple; cependant dans les terres gagnées fur les eaux par le defféchement, où il faut abforber la furabondance des fucs nourriciers, la même récolte du tabac pendant quatre ans ne rend le fonds que plus propre à porter d'autres fruits; \& certainement il exifte de ces fonds en Europe, fur-tout dans les marais \& dans les terres defféchées, baffes, graffes \& $\mathrm{li}$ moneufes, telles que je les ai ici annoncées.

Au refte, fi le tabac n'a point le droit d'y pouvoir végéter fans le fceau du Souverain, on peut encore épuifer la richeffe de ces fonds par les chanvres, les lins ramés, les colfats ceillettes ou grands pavots, les camomilles, \&rc., 
tous grains huileux \& effentiels pour les manufactures, la marine \& les arts; \& même les oignons qui y viendroient auffi gros que ceux d'Egypte. Je n'expliquerai point la culture de toutes ces graines qui n'eft que trop connue, j'en ai donné plufieurs mémoires imprimés dans quelques journaux françois, il y a long-temps. Les fonds ici défignés doivent être mis en avoine ou en orge, pour pomper l'exubérance des fucs \& des fels nourriciers; on la donne en verd, fi elle vient trop forte, finon on la laiffe mûrir, il faut $y$ femer le printemps fuivant du chanvre, le printemps d'après du lin ramé par un beau temps, après avoir bien adouci la terre à la herfe, à la charrue, puis des ceillettes, \& alternativement du lin, du chanvre, des oignons, de l'avoine, tant que la terre ne foit plus trop forte, \& qu'elle puiffe être femée en bled avant l'hiver, ou en bled de Mars, orge, paumelle, riz - fec.

Urit enim lini campum feges, urit avena;

Urunt Lathooo perfufa papavera fomno;

Sed tamen alternis facilis Labor. . . . . . .

Virg. Georg. Lib. I:

Toures ces plantes defsèchent ces terres graffes \& humides, \& les difpofent à porter du froment: 


\section{8}

le Colon y trouve un très-grand profit fans dépenfe d'engrais ; tous ces grains font femés au printemps; ils ne courent pas les rifques des hivers trop rigoureux ou trop doux, qui font périr le plus fouvent ces grains d'hiver:

Il eft de ces fonds privilégiés par leur pofition \& leur qualité fupérieure, qui rapportent tous les ans des récoltes très-abondantes \& très-précieufes. Ces terres femées en lin portent encore immédiatement après qu'il eft enlevé, dans la même anmée; une feconde dépouille, foir en navets, foit en plançons de colfat : ces fruits, loin d'épuifer le terrein, ne font que le rendre plus propre à porter de bon froment \& de bon feigle, \&c. , qui auparavant auroient fondu \& feroient pourris dans le champ. Quand donc cette ext-: bérance des fucs eft enlevée, on cultive cette. terre conme tout autre champ mis de longue main en culture, en femant du colfat, du bled, vefce, hivernace, féve, lentille, avoine ; ce font: autant de récoltes gagnées fans dépenfe d'engrais.

Sic quoque mutatis requiescunt fotibus arva.

$$
\text { Virgil. }
$$

Rien n'eft plus yrai que la variété des fruits \& des productions répare les terres : $\mathrm{Si}$, nonobftant tous ces foins, on voit, dès les premières dépouilles, 
dépouilles; que les herbes étouffent les productions; quand le gazon eft pourri, on resème ces terres en avoine; auffitôt qu'elle eft levée, on $y$ sème quinze ou vingt livres de trèlle à l'arpent, qu'on donne l'année fuivante en verd au bétail, tant qu’il dure; l'année fuivante on le laiffe engazonner \& enherber : il deviendra un excellent pré à faucher, ou à faire brouter par le gros bétail.

Dans toute la méthode ici expofée, je crois quil y a un profit réel, bien plus avantagenx que de laiffer en friche de bons terreins; le Culivateur y trouve toujours du bénéfice, plus d'engrais \& plus de moyens d'amélioration; on fauche plus fouvent les prairies artificielles que le pré naturel qui ne donne qu'une fois, puis un regain.

On objectera qu'il y a moins de frais, moins de dépenfes pour ce dernier : oui, fans doute; mais ne font-ils pas bien compenfés par le produit de toute efpèce? Par-tout où on travaillera la terre, comme je crois l'avoir fait fentir, on aura plus de beftiaux; outre cela ; on récoltera plus abondamment du froment, méteil, feigle, orge, maïs; en fus \& en pur gain, des lins, colfats, chanvre, camomille, lentilles, vefces, fèves qui fourniffent des nourritures aux hommes, Reftaur. de l'agriculture, Ex. D 


\section{0}

aux beftiaux, \& des denrées, comme je l'ai dit', pour le commerce, les manufactures \& les arts; au lieu qu'avec les prés naturels on n'a que des beitiaux, \& encore en plus petit nombre qu'en mettant une partie du terrein alternativement en prairie artificielle.

Les marais noyés fous l'eau ne doivent done pas même être exceptés, à moins qu'il n'y ait de la tourbe dont l'extraction eft bien avantageufe pour le chauffage, \& les cendres pour l'engrais des terres', à moins encore qu'ils ne foient fi humides \& d'un fi mauvais fonds, qu'on ne puiffe les planter qu'en aulnes, ofiers, faules $\&$ autres bois aquatiques. Quand on les a faignés, on les laiffe en pré naturel pendant quelques années; on y met les beftiaux : la terre s'affermit infenfiblement fous leurs pieds; on fait des foffés droit au nord \& au midi, d'autres à l'orient \& à l'occident; dans les plus bas fonds qui font ordinairement les plus tourbeux, on forme des étangs par l'extraction de la tourbe, qui dédommagent amplement les Entrepreneurs de cette opération, en coupant le terroir toujours tranfverfalement: on vient enfin à bout de les cultiver comme les terres les plus sèches \& les plus élevées, avantage qu'on n'obtiendra jamais, en les laiffant en 
pré ordinaire ou naturel; fi ce n'eft qu'ils fournilfent des foin fi abondans \& d'une qualité fi exquife, qu'il y auroit de la folie à les défricher.

Pour peu qu'on life l'hiftore-des anciens Peuples, on voit qu'ils ont toujours eu des bois immenfes à abattre, à deffécher des bas - fonds qui rendoient le pays mal-fain \& inepte, à la culture; les bêtes féroces dominoient impérieufement cette nature agrefte : le travail \& l'induftrie de l'homme adif ont tout furmonté. Dans le Nouveau- . Monde, ce font les mêmes opérations: ceux qui cultivent d'abord les terreins élevés $\&$ arides, fe rebutent bientôt; redevenus plus fages par leur expérience propre, ou celle des voifins, ils abandonnent les hauteurs pour deffécher \& cultiver les plaines \& $\&$ les fonds bas qu'ils avoient négligés. Ce changement ne doit furprendre perfonne, puifque dans l'Europe, dépuis fi long-temps policée, \& aujourd'hui fi éclairée, il faut que des Sociétés patriotiques propofent par-tout des prix, pour convaincre les Gouvernemens de l'urilicé des defféchemens \& des profits quion peut retirer des marais qui, pour la plupart, font des bas - fonds.

Aufli la première dépenfe pour les marais doir être faite par le Gouvernement; cette opération

$\mathrm{D}_{2}$ 


\section{is}

mérite l'attention des propriétaires patriotés les plus puiffans \& les plus éclairés': s'il faut descanaux pour faciliter l'écoulement des eaux, s'il faut les faire paffer par les poffeffions des perits \& des grands propriétaires, sil faut fupprimer des moulins à eau nuifibles, \& inondant tout un pays, les particuliers feront-ils en état de fe faire entendre, feront-ils écoutés ? d'ailleurs iront-ils expofer à l'aventure leur pecit pécule, pour un bien futur dont ils n'auront peut-être aucun profit? C'eft donc au Souverain à mettre la première main à ces travaux, \& à encourager les cultivateurs patriotes qui s'expofent à des tentatives fi périlleufes : c'eft une avance fóncière dont plus tard il eft amplement dédommagé ; à la place de ces eaux incommodes dont il n'a aucun tribut, autcun denier, vont naître des grains, des beftiaux de toute efpèce, des abeilles, de la cire, du miel, \& des hommes effentiels à la culture, \& d'aútres pour le commerce, les manufactures, les atts, la marine \& la gaerre : fi elles reftent croupiffantes, leurs exhalaifons empoifonnées portent dans tout le pays le germe des maladies les plus rebelles \& la mort.

Il me femble que cet expofé fait affez fentir N'utilité de cette méthode, 'la préférence qu'elle 


\section{3}

mẻrite, \& fa fupériorité fur tant d'autres qu'on vante beaucoup; tout ce que j'avance eft fimple, \& appuyé fur l'expérience la moins fufpecte : toutefois pour ne point courir le hafard de fe tromper fur un ouvrage de pure théorie, on pourroit faire l'épreuve \& les efrais en petit de tous ces travaux qui n'appauvriroient perfonne.

On objectera peut-être que dans la manière que l'on propofe ici de défricher \& de culciver, on ne voit point d'année de repos, point de jachìre : non vraiment; c'eft là le principal but : files hommes ne fe rebutent point de mancuvrer la terre à la charrue \& fur-tout à la bêche, de l'aider d'engrais par lo moyen des prairies arrificielles \& des racines, telles que pommes de terre, carottes, panais, betteraves, navers, \& $c_{0}$, ils ne manqueront jamais de fubfiftance pour eux \& pour leurs beftiaux, \& par conféquent de fumier : la terre n'eft jamais laffe de produire des fruits profitables. Abandonnée à elle-même, ello en produit de mauvais \& infalubres, il faut la remuer avec une bêche d'or : cette cultute n'exclut donc point celle du bled, du feigle, de l'avoine, des fèves, des fcourgeons, du lin, du colfat, des cillettes, \&c.; au contraire elle la facilite \& la sorrobore : les fonds qu'on deftine au fain-foin

$D_{3}$ 


\section{4}

\& à la luferne ne font furement pas les meilleurs; ils font en repos pendant $5,10^{\circ}$, is ou 20 ans, plus ou moins, felon la qualité du fol; ils donnent le temps de rejetter tous les autres fumiers fur les meilleures terres qu'on cultive pendant ce temps, felon l'ancienne routine, avec piofit, en froment, lin, colfat, \&c., parce que les fumiers provenans des pailles font préférables pour. les grains, parce queles cendres de tourbe, de bois, fuie de cheminée, cendres d'houille, chaux, urine des beftiaux, latrines, \&c. , conviennent mieux aux prairies artificielles.

Si l'on mer des pommes de terre, carottes, panais, betreraves, navets, choux, ce n'eft jamais dans une grande quantité de terres; ce n'eft qu'à proportion de fes beftiaux \& de fon exploitation : on a toujours, malgré la récolte de ces fruits effentiels \& précieux, le même nombre de terres, ou peu s'en faut, en bled, en:feigle, en avoine, en fcourgeon, "\&c., comme dans les foles réglées \& de repos; le colfat, lin, œuillettes, fèves, carottes \&c., tiennent lieu de jachère; on sème du bled immediatement après leur dépouille, fans laiffer la terre en repos. Voilà la vraie richeffe d'un Colon intelligent, qui jet:e de l'or à propos fur fes terres par des avances 


\section{Ss}

foutenues \& réitérées qui le dédommagent toujours amplement de fes mifes, de fes foins \& de fes travaux par la fuppreflion des jachères.

Un royaume qui a quatre cents millions de revenu, en aura fix cent millions; \& bien plus, lorfque tout fera dans un état de foriffante culture, je trouve cette augmentation dans les grains huileux, tels que colfat, lin, chanvre, cillettes, \&c., qui donnent l'aliment au commerce, \& qui uccupent utilement l'année de jachères; dans. l'augmentation des beftiaux, des fuifs, des falaifons, des pelleteries, des laines perfectionnées, des nourritures, des fumiers, \&c. La terre ne fe laffe jamais quand on l'engraifle \& quand on la cultive bien; ce font les hommes inexpérimentés \& pauvres qui fe laffent \& fe rebutent; rien donc n'eft plus vrai qu'elle rend en proportion de ce qu'on lui donne; mais comme je l'ai dit, l'alternative \& la variété des productions réparent \& renouvellent les terres; les engrais nouveaux la rendent plus productive \& plus profpère.

Dans la culture des jachères, la terre produit toujours les mêmes fruits depuis le commencement d'un fiècle : dans la première année, du bled, méteil, feigle ou orge; dans la feconde

$\mathrm{D}_{4}$ 
année, de lavoine, vefce, ou lentille; enfin l'année du repos ou de jachères pour la troifième année, \& c'eft toujours le même cercle \& la mème ritournelle jufquà la fin des fiécles. Par If méthode propofée, il naît un nouvel ordre de chofes, il fe fait une autre révolution dans les efprits \& dans la culture ordinaire.

Je demande à tout homme de bon fens, files fucs \& les fels propres \& convenables à la croiffance du bled, feigle, avoine, \&c., ne doivent point s'épuifer par une longue fuite d'années, dans des fond's qui ne font pas riches \& privilégiés par leur nature, qui ne font jamais profondés à la bêche ni à la charrue, ou par de nouveaux engrais, d'autant plus que les principales racines de ces efpèces font en griffe \& n'atteignent que la fuperficie du fol, qui fouvent n'eft remuée que par de chetives charrues \& des labours légers; au lieu que dans la façon que $j$ 'indique, on manouvre bien autrement la terre : on la profonde, on la renouvelle, on la rajeunit, on l'engraiffe beaucoup plus, \& on le peut, parcé que l'on a plus de beftiaux, plus de cendres, plus de chaux \& alltres engrais nouveaux; $\&$ en fus plus de fumier. Le plus grand nombre des efpèces que je propofe à culiver, tels que fain-foin, luferne, trefle? 


\section{7}

chanvre, colfat, lin, oillettes, fèves, carottes; $\& c$. , ont des racines longues \&. pivotantes qui vont puifer au plus profond du fol, des fucs vivifians \& nouveaux, \& cependant morts dans l'autre culture. Les cendres de tourbe, la chaux mêlée enfemble, les fumiers \& les engrais tournent donc encore au profit des fromens, méteil, avoine, \&c. que tes racines n'ont point fucés. On peut donc par ces moyens, \& perit à petit, fupprimer les jachères.

Ceci me paroît fi clair, fi fimple \& fi facile à pratiquer, qu'il feroit fuperflu de s'étendre davantage là-deffus; mais les gens de la campagne ne s'en rapportent point, pour l'ordinaire, aux follicitations ni aux mémoires écrits: il leur faut des démonftrations palpables, parlantes aux yeux \& fortifiées par les épreuves, l'exemple \& les fuccès d'un étranger ou d'un voifin : ils s'en mocquent malgré cela dans le commencement, parce qu'il cultive autrement qu'eux. C'eft bien parmi cette claffe d'hommes que les préjugés font plus difficiles à vaincre \& à furmonter : les femonces \& les injoncticns n'y font rien; il faut donc prendre des voles plus douces, \& cependant qui atteignent p'us surement le but qu'on fe propofe: c'ent le bon exemple d'un propriétaire os d'un agriculteur riche 
 \\ 58}

\& entendu, je l'ai déja trop répété, \& c'eft le mot de l'énigme rurale.

Les travaux fans ceffe renaiflans des hommes utilement occupés, \& l'aifance qu'ils leur procurent, réveillent-chez eux l'activité \& l'induftrie; l'intérêt les anime, l'émulation les aiguillonne: ils deviennent plus éclairés, ils voient tous les jours de trop près les bienfaits de l'auteur de la nature, ils en jouiffent avec trop de reconnoiffance pour fe livrer à l'inaction \& à des fuperfitions populaires : il eft bien plus difficile de les induire en erreur que les peuples défceuvrés, \& conduits fouvent par un chef qui a intérêt de les tromper. Les manufactures, les arts \& l'aifance s'établiffent, appellent le bonheur, \& font fuir infenfiblement les préjugés \& les preftiges qui tiennent dans l'abrutiffement les hommes fauvages, les peuples Bárbares, \& même les Nations policées qui ne font point agricoles.

O Souverains de l'univers qui goutvernez les Nations, vraies images de la divinité, vous dont la volonté fait difparoitre les hommes, ou les fait naître à votre gré, puiffiez-vous être perfurdés qu'un impôt mal aflis \& arbitrairement perçu, qu'un 
édit mal combiné, fait autant de tort à vos états. que le vent fec \& brûlant du midi, ou la gelée hots de faifon en fait aux fruits, aux campagnes verdoyantes \& fleuries quils defsèchent entièrement.

La guerre peut faire périr des millions d'hom. mes; vous pouvez, ô porentats, ô peuples libres! fans beaucoup de peines; faire forrir du néant des milliards de générations nouvelles : protégez le cultivateur contre la finance, la chicane, \& toute oppreffion maltotière; encouragez-le, rendez-lui la liberté \& la nobleffe de fon premier étar; il fera riche, \& vous très-puiffans. 
MÉTHODE-pratique de semer et planter le colsat à la maniere flamande.

Imprimée à Paris, au Bureau royal de correfpondance générale, rue des Deux-Portes Saint-Sauveur; Février 1773.

Nihil agriculturấ melius, nihil uberius , nihil homine libero dignius.

Cic. de Offic.

IL y a trois fortes de terres; la glaife, le fable; la marne. La glaife, mêlée avec une portion de fable, eft ce qu'on appelle argille. Les différentes combinaifons, les différens mélanges de ces terres compofent la variété infinie de tous les fols, \& $c^{\prime}$ eft ce qui leur fait donner ces dénominations particulières : marneux, où la marne domine; glaifeux, où la glaife eft en plus grande quantité; fableux, où le fable prévaut. A proprement parler, il n'y a que deux fortes de terres: l'une forte, \& l'autre légère; leur mélange leur fait donner différens noms. Leurs couleurs font aufi variées que leur nature \& leurs propriétés; la glaife eft la plus compacte $\&$ la plus tenace, celle que l'agriculture doit le plus divifer, remuer \& rendre 
61

légère par le moyen du labourage, ou le mé lange d'une autre terre, ou engrais plus léger. Le fable eft ordinairement léger, vole au vent. Le labourage ne doit pas être fi fréquent fur ce fol; mais il faut y multiplier les engrais les plus gras, les plus compacts pour lier fes parties incohérentes \& divifées. La marne pure \& propre à faire de la chaux, eft excellente pour échauffer les terreins froids \& humides; la marne sèche, craye ou crayon y eft propre aufi, mais principalement pour divifer les fonds glaifeux, trop argilleux, \& dont les pores font trop ferrés. $\mathrm{La}$ marne graffe \& glaifeufe eft merveilleufe dans les fonds de nature légère; elle relie les parties féparées, \& leur donne la confiftance néceffaire dont elles étoient dépourvues.

Je crois que la fcience du Labonreur fe rédüit a rendre les terreins compacts affez divifibles \& fpongieux, pour que la ftagnation des eaux pluviales \& d'hiver ne pourrifle point la racine des plant ss \& $z$ des grains, lis abreuvant des fels inhérens au fol, de ceux dont l'atmofphère l'imbibe; \& de ceux dont linduftrie du Cultivateur l'enrichit. Dans un fens contraire, les terreins, trop légers qui volent au vent ou s'affaifent trop (ce qui met à découvert toutes les racines, les fair geler ou langnir, périr enfin), doivent fubir une op:- 
62

ration toute différente, \& qui donne du corps $\& \dot{z}$ de la confiftance à leur légèreté. La plupart des fonds fur lefquels l'agriculture n'exerce pas toute fa vigueur, ne font jamais remués bien profondément. Quand, en fillonnant la terre, le Laboureur ramène à la fuperficie une terre plus dure, plus compacte, ou d'une couleur différente de la couleur ordinaire, il dit: cette terre ne vaut rien; il n'ofe la percer plus avant; de forte que l'eau fejournant toujours fur cette croûte, réfroidit le fol, empêche la végétation, le pivotement des racines, \& nuit on ne peut pas davantage à l'accroiffement des plantes. En ruiffelant la terre de huit pieds en huit pieds par planches égales, on commence à donner un écoulement aux eaux; le mélange de la terre, tirée du fonds des rigoles ou ruifeaux dont nous parlons, avec celle de la fuperficie, va rajeunir tout le fol : deux ou troiś ans après on renouvelle la même befogne, c'eft-à-dire qu'on ruifelle encore la terre dans l'endroir le plus bombé, ou le milieu des anciennes planches. Le fein de la terre, ainfi déchiré à fonds par plufieurs reprifes \& en tout fens, ne fera plus noyé; les racines trouvant une terre meuble, s'étendront en liberté, \& pomperont les fucs propres à leur efpèce ; les fonds de ta Flandre, bons ou médiocres, ont été fi fouvent ruiffelés \& déchirés de 
$6_{3}$

long \& de large, en croifant, \& de tant de mâa nières avec la charrue ou la bêche, que dans certains cantons, les plus fubltanciels y font fort légers à une très-grande profondeur: auffi, quelle variété dans les productions du pays, quelle fécondité ! on la dit inépuifable. On l'attribue, mal-à-propos, à l'excellence du fol; elle n'eft due qu'au travail, à la dépenfe continuelle \& à l'induftrie infatiguable de fes laborieux habitans. Les engrais y font fort chers: peu importe, il faut en avoir; on en fait, on en achète à quelque prix que ce foit. Oui. Mais, dira-t-on, il faut bien de l'argent \& des richeffes pour fournir à toutes ces dépenfes : j’en conviens, auffi dit-on qu'il faut remuer la terre avec une bếche d'or, que l'agriculture haï pauvreté; que fans avances on ne peut faire aucune dépenfe, \& fans dépenfe, point de récolte; enfin, pauvres Laboureurs, pauvres moiffons; pauvres moiffons, pauvres villages; pauvres villages, pauvres Provinces; pauvres Provinces, pauvres Royaumes. Ce préambule un peu aride ent cependant nécelfaire pour faire entendre la culture flamande du colfat \& des autres grains.

Autant qu'il eft poffible, il faut déchirer la terre avant l'hiver, ce que l'on appelle donner une 
64

raye avec la charrue qu'on nomme bine (I), binoit ou binot. Enfuite il faut la herfer, puis y voiturer du fumier bien pourri. Cependant fi les terres font en bon état \& affez graffes, il n'en faut pas, parce que trop de fumier fait venir la tige trop haute, moins bonne à planter, \& plus foible pour réfifter aux gelées ; fi l'on n'a pas pü y porter du fumier avant l'hiver, il faut néceffairement en mettre au mois de Mars, l'enfouir au binoit, puis herfer, enfin donner un fecond labour avec la charrue tourne-oreille ou le brabant. Peu de temps après bien herfer, enfuite retourner la herfe fur le dos avec lequel on applatit le terrein; ce qui empêche la séchereffe d'y pénétrer: en langage du Pays on appelle cela ploutrer. Vers ie

(1) Bine, bince aures, fignifie charrue à deux oreilles immobiles.

L'autre charrue a une oreille de fer ou de bois, mobile, \& le brabant ou le loup qui a auffi une oreille immobile, \& qui n'a point de roues; fon axe porte fur un petit patin qu'on remonte ou hauffe à volonté, ce qui enterre ou déterre la charrue plus ou moins. Elle eft excellente pour les défrichemens \& les terres furtes; c'eft la plus expéditive \& la meilleure de toutes celles que je connois; on n'arrête jamais : on va toujours en avant, \& en tournant au bout de chaque champ.

premier 


\section{os}

premier de Juillet ou environ, il faut un rroifième labour avec l'une ou l'autre charrue; herfer \& ploutrer comme ci-deffus. Vers le 20 du même mois on sème le colfat, on pince la graine avec le pouce \& les deux premiers doigrs fuivans; pour la femer, le femeur doit embraffer deux bons pas, fur-tout il doit fe garder de femer dru; un tour de herfe fuffit pour la couvrir ; deux livres ou deux livres \& demie de graine fuffifent pour un arpent de terre.

A la fin de Seprembre, cette plante doit être arrachée avec la racine, mife en bottes pour être tranfplantée à la main, jufqu'á l'œillet, dans une autre terre qu'on prépare de la manière fuivante. Les feuilles les plus près de la racine font trèsbonnes pour les vaches.

On peut planter le colfat après toutes fortes de récoltes. La dépouille du champ étant enlevée, il faut biner ou binoter, c'eft-à-dire, labourer avec la bine \& la herfe, pour détruire l'herbe de la fuperficie, voiturer de bon fumier, (tous engrais font bons) enfuite l'enfouir avec la charrue tourne-oreille oule brabant, par planches; c'eft-à-dire qu'on trace huit raies, \& que la huitième refte ouverte; c'eft de ce fillon ouvert qu'on tire avec la bêche la terre qui, plus tard,

Reftaur. de l'agriculture, $\varepsilon_{c_{0}} \quad \mathrm{E}$ 
rechauffe, regarnit la plante du colfat, \& ra= jeunit le terrein. Ce font des femmes, des perits garçons, des jeunes filles qui plantent le colfar: ils en prennent un faifceau fur le bras gauche, de la main droite ils empoignent quatre ou cinq plantes plus ou moins, felon leur groffeur, les enfoncent une à une, à-peu-près jufqừ l' l'oillet, dans des trous qu' un homme vigoureux fait avec un inftrument garni de deux groffes dents de fer. Cet homme va toujours en reculant, brife les mottes, \& applanit le terrein avec les pieds. S'il y a trop de mottes, on paffe la herfe fur la planche pour adoucir la terre. Cet homme fait les trous par rangées \& rourtes. Chaque rangée a un pied; chaque plante eft à quatre pouces de diftance; chaque trou doit être rebouché par le planteur, en appuyant le pied fur la terre près de la racine, comme on plante les choux ou les porreaux.

Vers le mois de Novembre, on envoie des ouvriers fur le champ de colfat : ils prennent avec une bêche un bon pied de terre de profondeur $\&$ un pied de largeur, dans le fillon refté ouvert de chaque pianche; ils jettent cette terre à droite \&r à gartche entre chaque rangée, le plus près poffible des racines, fans néanmoins couvrir les fevilles \& 1 a tige. Cetre opération garantit la 


\section{7}

plante de la gelée, \& lui donne une nonvells terre. Att printemps, on prend encore ordinairement un demi-pied de terre, plus ou moins de profondeur, dans les ruiffeaux ouverts; on jettc auffi cette terre entre chaque rangée de colfat, pout regarnir \& rechauffer les racines, \& lui 1 fournir une terre nouvelle qu'on tire également du fords des ruiffeaux de chaque planche.

A la Saint-Jear on récolte ordinairement : le grain commençant à nöircir, on le fcie, on l'étend par javelles en attendant qu'il foit affez mûr pour. le battre fur le champ même, où on le met en meule pour attendre à le battre au mois de Septembre ou d'Octobre, fur une grande toile près. de la meule : on le crible, on le vend pour faire de l'huile bonne à brûler, ainfi que pour les draps, favonneries \& autres manufactures. IL marc eff un très-bon engrais pour les terres, $\&$ fert auff très-bien à engtaifer les bètes à comes $\&$ les moutons. La gouffe qui lienveloppe fert aufi de sourriture l'hiver à ces derniers. Sa tige rameufe, fert très-bien à chauffer le four, à couvrir les tô̂rs. des maifons ruftiques, à la litière des beftiaux. quand on manque de paille. La cendre en eft merveilleufe pour la leflive; quand on en met trop, fa force écorche les mains des Lavandiesesog

E 2 


\section{8}

La racine fert à chauffer les pauvres, tout eft bon dans cette précieufe production; mais le plus grand avantage qu'elle donne à l'agriculteur, c'eft de lui fervir de jachère ou d'année de repos, de rajeunir fon terrein, de rendre les terres qui font trop dures \& trop humides, plus fpongieufes, plus légères, \& plus propres à porter dans la fuite toutes fortes de grains, fur-tout du froment.

Cette plante donne du travail à quantité de manouvriers qui meurent de faim dans les Provinces où elle n'eft point cultivée; elle fournit beaucoup au commerce par fes huiles, comme à l'engrais des beftiaux \& à l'amélioration des terres. par fon marc.

En-tenant lieu de jachères, elle donne à.la fin les moyens de les fupprimer toutes. Si les Provinces. qui ignorent fon ufage la cultivoient, il y auroit un tiers des terres condamnées à repofer, qui produiroient une excellente récolte ( $\mathrm{I}$ ), qui éclaire \& chauffe le pauvre à bon marché, couvre fa cabaine plus folidement que le chaume ordinaire; lui fait tirer meilleur parti de fon petit champ \& de fon bétail, lui donne les moyens \& l'envie de

(I) De manière qu'un Royaume qui produit, année commune, 800 millions, en produiruit au moins 1200. 


\section{9}

cultiver le lin, les aillettes, camomilles, chanvre; garance \& autres productions précieufes qui l'enrichiffent, lui donnent la facilité de mieux payer les charges, de faire des defféchemens \& défrichemens, \& bannit enfin la misère qui tient depuis fi long-tems les habitans des campagnes dans un abrutiffement léthargique \& déplorable.

Cette plante a un défagrément; c’eft que le lièvre, le lapin, le faifan, la perdrix en font fort friands, \& que leur chair, quand ils s'en nourriffent, contracte un goût huileux $\&$ de choux; elle eft beaucoup moins fine que celle du gibier des landes, des bruyères, des terres arides \& incultes.

Un domaine bien cultivé qui procure un bon revenu affuré, qui tire les hommes de la pareffe, de la mifère, du néant, ne nous dédommage-t-il point de ce léger inconvénient? lequel vàut mieux d'avoir une valte folitude, repaire de bêtes nuifibles, ou de beaux villages floriffans \& couverts d'une vigoureufe population, bien nourrie, qui paye gaiement l'impôt \& de bons fermages? Ces petites inftructions peuvent fuffire à de bons Cultivateurs qui donneront l'exemple. Les haricotiers feront les derniers à le fuivre, parce qu'il en 
cotite beaucoup de frais; des Laboureurs dans l'aifance \& peu clairvoyans mépriferont cette méthode; mais l'exemple de la Flandre, qui s'eft toujours trouvée dans l'abondance, même au milieu des plus fortes crifes, doit faire ouvrir les yeux aux plu's opiniâtres. C'eft dans cette Province qu'on ne voit plus un pouce de jachères, \& la terre rapporte deux récoltes dans la même année. Il eft vrai que quand le commerce des grains farineux de province à province n'étoir pas libre, celui des huiles n'étoit point gêné; c'eft pourquoi les Laboureurs cultivoient davantage ce quils pouvoient vendre à profit, le colfat, le lin, chanvre, cillettes, camomille, \&c.

\section{Conclufions.}

On voit que par la culture du colfat on peur técolter deux fromens en trois années: la première en froment, puis l'année du colfat qui tient lieu de jachère \& d'une très-bonne jachère, \&r enfin la zroifième encore en froment par de nouveanx fumiers par le remuement \& le renouvellement des terres; on peut de même, après le lin, les cillettes, les fèves, veíces, févelottes, \&c. , récolter immédia- 


\section{$7 \mathrm{I}$}

tement du froment, du feigle, parce que; quand la terre eft bien graffe \& bien cultivée, on a encore de bon froment après chacune de ces productions, \& par conféquent point de jachères.

F I N: 
178
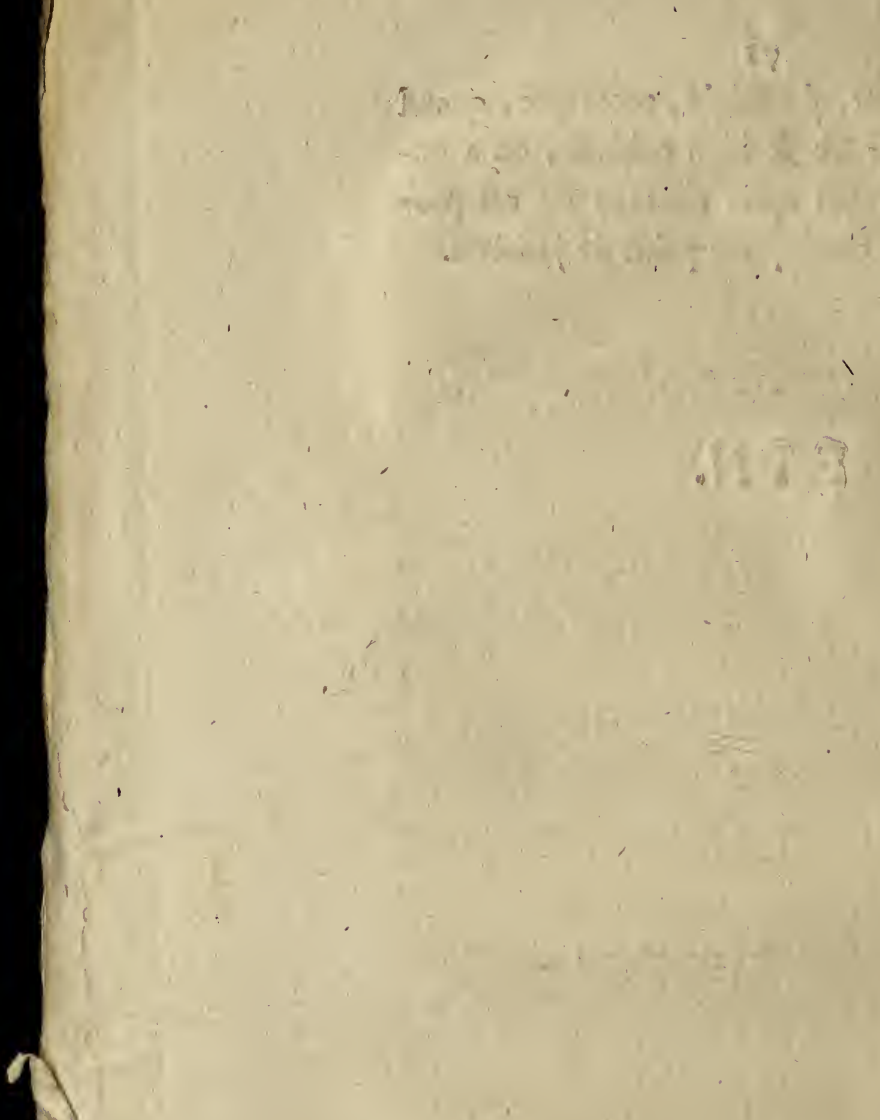